\title{
Action is required to safeguard the future of academic medicine in the UK
}

\author{
Garth M Funston \& Adam M H Young
}

\begin{abstract}
The long-term decline in the number of UK doctors who conduct research is well recognized. Although some signs of recovery have been noted in the last few years, government budget cuts and the imminent rise in the tuition fee cap may make a bad situation worse.
\end{abstract}
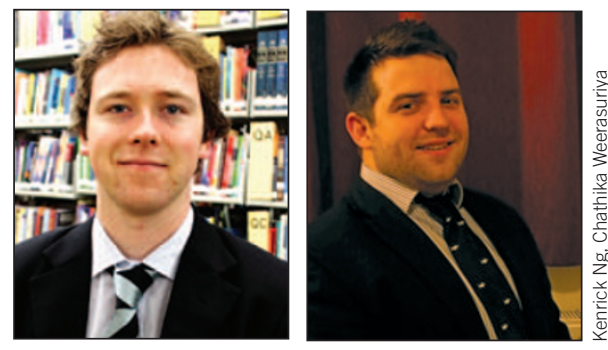

Fewer doctors are entering academic medicine in the UK, with the number of full-time clinical academics having fallen by $10 \%$ over the last decade'. In reaction to dwindling numbers, the 2005 'Walport report' laid out a series of recommendations to tackle the "perilous state of academic medicine in the UK." Among the initiatives that came from the report, the Academic Foundation Programme (AFP) provides opportunities for a small proportion of junior doctors to undertake research during the first or second year after graduation. In addition, a clearly defined, but flexible, academic career pathway now exists, providing guidance for those considering academia.

The UK may already have seen some benefit from these programs. For example, the number of clinical academics increased by $2 \%$ between 2009 and 2010. But the aging population of clinical academics is of concern, with $63 \%$ of clinical academics being over the age of 46 in 2010 compared with only $53 \%$ in 2004 (ref. 1). It is clear that action must be taken to promote academic medicine to the next generation of students and junior doctors.

The need to attend to this problem is even more urgent with looming tuition hikes that threaten to undo whatever progress might have been achieved through the AFP and structured career pathways. New students starting medical school from September 2012 are set to pay $£ 9,000(\$ 13,800)$ per year in tuition fees, a considerable rise from the previous fee of $£ 3,375$. And although the standard medical course in the UK lasts five years, most medical schools offer a six-year option with a year of research, resulting in an additional Bachelor of Science degree. This six-year option, known as an intercalated degree, is undertaken by roughly one-third of students ${ }^{2}$.

The intercalated degree provides a vital first taste of research that inspires many to continue on an academic path. However, owing to the substantial rise in tuition fees leaving students with an ever greater burden of debt, there is a serious risk that they will avoid this program, with its extra year of debt and delayed earning potential, and also reject research opportunities during their vacations in favor of better paid work.

In contrast to the US system, medicine in the UK is predominantly an undergraduate degree, so students will not have had prior research opportunities. Also, most doctors in the UK who undertake a $\mathrm{PhD}$ do not begin until five to six years after graduation from medical school, with MD-PhD schemes being relatively uncommon. Thus, intercalated degrees and vacation research projects are an early but integral part of the academic career path in the UK, and few doctors would consider a PhD unless they have become hooked on research at this stage.

Only a handful of grants exist to help support students undertaking intercalated degrees, with a small number also available to fund vacation projects. This funding is predominantly provided by both large and small charitable bodies. However, such schemes are often poorly advertised to students and have complex application systems, and there seems to be no effort to coordinate these schemes on a national level. It is imperative that universities, charities and government and publicly funded bodies collaborate to assess whether the current schemes are sufficient, in terms of both number and the stipend they provide. If insufficient, greater funding must be provided by these organizations to ensure that students are not denied the opportunity to undertake research because of personal financial constraints.

A sign that the challenges are being recognized is the recent award of a $£ 1$ million grant to the Academy of Medical Science (AMS) by the Wellcome Trust, with the aim of 'inspiring medical students with research'. When Nature Medicine went to press, an AMS scoping study was underway to determine how this money could best be spent to achieve this aim.

We have both taken intercalated degrees and spent most summers during university working in labs. As a result, we have developed a passion for research and a strong desire to pursue research careers. In November 2011, along with other students from across the country, we helped launch the UK's National Student Association of Medical Research (NSAMR). To our knowledge, NSAMR is the first national, student-led initiative of its kind in the world that aims to promote research and academic medicine to medical students. Financed by a Wellcome Trust grant, it offers funding to a group of students at each UK medical school to form a local student-led research society. We hope to link these societies together through NSAMR to establish a collaborative network of interested students throughout the country.

The NSAMR will not only connect students with an interest in research to each other and to academics but also provide opportunities for students to present their research on a national stage and reward excellence. The organization planned an inaugural conference, that took place in London on 4 February, to bring together 100 students from 21 of the 32 UK medical schools to present high-quality original research to their peers and to leading researchers. We believe that NSAMR represents an innovative approach that will inspire students to undertake research. But organizations such as NSAMR rely on the provision of student research opportunities including intercalated degrees.

There has arguably never been such an exciting time to be involved in research. It is essential that we inspire students and maintain, or perhaps expand, funding and support to allow students to experience this excitement first hand. We must step up efforts to reverse the decline in doctors pursuing an academic career path to ensure continued progress in the fields of science and medicine.

Garth M. Funston and Adam M.H. Young are final-year medical students at Cambridge University and founding Chair and Deputy Chair, respectively, of the UK National Student Association of Medical Research.

1. Fitzpatrick, S. A survey of staffing levels of medical clinical academics in UK medical schools. <http://www.medschools.ac.uk/AboutUs/Projects/Documents/Clinical_ Academic Staff Survey as at July 2010.pdf> (2011).

2. McManus, I.C., Richards, P. \& Winder, B.C. BMJ 319, 542-546 (1999). 